\title{
Neurobehavioural evaluation of Venezuelan workers exposed to inorganic lead
}

\author{
Neil A Maizlish, Gustavo Parra, Oscar Feo
}

\begin{abstract}
Objectives-To assess neurobehavioural effects of low exposure to lead, 43 workers from a lead smelter and 45 workers from a glass factory were evaluated with the World Health Organisation neurobehavioural core test battery (NCTB) in a cross sectional study.
\end{abstract}

Methods-The NCTB comprises a questionnaire and seven tests that measure simple reaction time, short term memory (digit span, Benton), mood (profile of mood states), eye-hand coordination (Santa Ana pegboard, pursuit aiming II), and perceptual speed (digit-symbol).

Results-Smelter workers were employed on average for four years, and had a mean blood lead concentration of $2 \cdot 0$ $\mu \mathrm{mol} / 1$ (42 $\mu \mathrm{g} / \mathrm{dl})$. Glass factory workers had a mean of $0.72 \mu \mathrm{mol} / /(15 \mu \mathrm{g} / \mathrm{dl})$. Historical blood lead concentrations were used to classify exposure based on current, peak, and time weighted average. Although the exposed workers performed less well than the non-exposed in 10 of 14 response variables, only profile of mood states tension-anxiety, hostility, and depression mood scales showed a significantly poorer dose-response relation with blood lead concentration in multiple linear regression models that included age, education, and alcohol intake as covariates. The frequency of symptoms of anger, depression, fatigue, and joint pain were also significantly increased in the exposed group.

Conclusion-This study is consistent with the larger body of neurobehavioural research of low occupational exposure to lead. The small effects found in this study occurred at blood lead concentrations slightly lower than those reported in several previous studies.

(Occup Environ Med 1995;52:408-414)

University of California, Berkeley, California, USA

N A Maizlish

Occupational Health Unit, University of Carabobo, Maracay, Venezuela

G Parra

O Feo

Correspondence to:

Dr Neil Maizlish, 1226 Carlotta Ave, Berkeley California, USA 94707.

Accepted 30 January 1995 variation in methods, exposure patterns, and population characteristics, among other factors.

Several different standardised neuropsychological test batteries have been given to more than 1000 workers with an average of two to 13 years of exposure and whose blood lead concentrations averaged between 1.0 and $2 \cdot 7 \mu \mathrm{mol} / 1 \quad(22-56 \mu \mathrm{g} / \mathrm{dl})$. Low exposure to lead seems to affect a broad range of psychological functions, including mood, ${ }^{1278}$ simple and choice reaction time, ${ }^{6712-1417}$ short term memory, 34101317 spatial reasoning, ${ }^{3101316}$ perceptual speed, ${ }^{6} 1316$ and eye-hand coordination. ${ }^{1013}$ Long term follow up of workers has been attempted less often ${ }^{1-2} 1014$ and suggests that psychological function deteriorates with continued exposure, ${ }^{10}$ but recovers after the end of exposure. ${ }^{1}$

To correct the lack of standardisation in neurobehavioural assessment, the World Health Organisation (WHO) neurobehavioural core test battery (NCTB) ${ }^{19}$ has been advocated as a validated, standardised psychological test battery that has been reported to be transcultural. ${ }^{20}$ The purpose of this investigation was to apply the NCTB to confirm whether effects reported in the European and North American scientific literature were also occurring in a population of Venezuelan workers exposed to lead. A specific aim was to explore indices of exposure based on blood lead concentration to determine which were sensitive predictors of altered neurobehavioural function.

\section{Material and methods}

STUDY DESIGN AND POPULATION STUDIED

The study was cross sectional in design and subjects were enumerated and drawn from two industrial populations: a secondary lead smelter (exposed group) and a nearby glass factory (non-exposed group) in the state of Aragua, Venezuela.

The smelter workers belonged to a union and were employees of a multinational company that had operated in the same two hectare site since 1986 . On average 100 people were employed, including a few managers $(<10 \%)$. Stable employment patterns had prevailed until the first quarter of 1993 when nearly one third of the workforce was replaced with new workers. Eligibility to our study was restricted to the 43 long term production workers hired between 1986 and 1992 (inclusive), who were still employed in July 1993, when the workers were studied. 
The material handling department $(n=55)$ at a large glass factory was the source of nonexposed workers. The site was chosen because of the geographic proximity and availability of workers performing tasks with similar mental and physical demands as the lead workers, but without exposure to lead. The department was visited in person by industrial hygienists before the study began to confirm that neurotoxins such as solvents or lead were not present.

Eligibility to participate was restricted to production workers, and because all smelter workers were men, the eligibility of subjects at the glass factory was likewise restricted to men.

\section{EXPOSURE AND CLASSIFICATION OF EXPOSURE}

Lead ingot production, roughly 1000 tonnes a month, consisted of cracking and crushing car batteries, separating the lead components from the plastic casings, crushing lead components in a grinder, melting the grindings in induction furnaces, pouring molten lead, removing dross, and casting ingots. The production area, although under a roof, was not walled in, and local exhaust ventilation was not used. A baghouse was present to capture furnace emissions. The maintenance building, yard for stacking batteries, and plastic recycling area were located in the immediate vicinity. Job rotation was a company policy. Shower facilities and clothing change area were separate from, but near the production areas. In recent years, workers were provided with half mask air purifying respirators.

Since 1986, blood lead was monitored under a physician's supervision at the lead smelter. Test results for quarterly screenings for each of several years were available for all of the eligible long term lead workers. At the time of this study, the glass factory workers (non-exposed group) were also requested to provide $10 \mathrm{ml}$ samples of venous blood by venepuncture from a forearm for blood lead analysis. Historical blood lead analyses at the smelter and 1993 samples from the glass factory workers were analysed by the same internationally accredited laboratory with identical methods. Airborne lead measurements were not available for this study.

Based on sampling criteria (exposed and non-exposed) and blood lead concentrations, exposure was classified in four ways that reflected intensity and duration of exposure.

(1) Dichotomous: dichotomous categories (exposed and non-exposed) from the two populations sampled.

(2) Current: defined as the blood lead concentration $(\mu \mathrm{mol} / \mathrm{l})$ taken most recently before testing (usually less than three months).

(3) Peak: maximum blood lead concentration $(\mu \mathrm{mol} / \mathrm{l})$ recorded between 1986 and 1993 for the smelter workers, and the single measurement for glass factory workers, which was assumed to reflect peak concentration.

(4) Time weighted average (TWA): the product of the time and the concentration $(\mu \mathrm{mol} / 1 \times$ years $)$ taken over the course of employment divided by the overall time period. For smelter workers, the TWA exposure is given by:
TWA Pb (blood $)=\frac{\sum\left(\frac{P b_{i}+P b_{i+1}}{2}\right) \times\left(t_{i}-t_{i+1}\right)}{\sum\left(t_{i}-t_{i+1}\right)}$

where $\mathrm{Pb}$ is the blood lead concentration of the ith time ordered sample and $t$ is the time (date) the sample was taken.

For the glass factory workers, the single blood lead measurement was also assumed to reflect average exposure.

\section{NEUROBEHAVIOURAL CORE TEST BATTERY (NCTB)}

The purpose of the WHO neurobehavioural core test battery ${ }^{19}$ is to measure a broad range of neurobehavioural functions in four domains: psychomotor speed and dexterity, memory, mood, and visual-spatial ability. The tests took about 50 minutes a subject with mostly pencil and paper, and were given face to face by a trained and experienced physician-interviewer in a room free from noise and distraction. All tests had previously been translated from English to Venezuelan Spanish, pilot tested, and revised, when necessary. ${ }^{21}$

The occupational and medical questionnaire covered work history, including previous exposures to neurotoxic substances; medical conditions and medications; lifestyle exposures to neurotoxins (tobacco, alcohol, hobbies); and 21 symptoms associated with neurotoxins or exposure to lead. ${ }^{1922}$

\section{Profile of mood states}

The profile of mood states questionnaire is one in which the subject rates himself on a scale from one to five about feelings experienced during the previous seven days. ${ }^{23}$ This includes 65 items and provides a six point mood profile: tension, depression, anger, vigour, fatigue, and confusion. The profile of mood states was a sensitive indicator of neurotoxicity in a previous study of smelter workers exposed to lead, ${ }^{2-3}$ and Venezuelan workers exposed to mixtures of organic solvents. ${ }^{21}$

\section{Simple reaction time}

Simple reaction time measures simple visual reaction time. The subject responds to a red light stimulus presented at delays from one to 10 seconds in a $2 \mathrm{~cm}$ window of a reaction timer by immediately depressing a small button with his index finger. The mean simple reaction time (ms) of 64 trials is the response variable. Slowed simple reaction time has been reported among smelter workers ${ }^{6713}$ and workers manufacturing ethyl lead. ${ }^{17}$

\section{Digit span}

Digit span, from the Wechsler adult intelligence scale, ${ }^{24}$ measures short term memory and attention. The tester recites groups of three, four, five, six, progressively up to eight numbers, and the subject is instructed to repeat the sequences in the correct order. The maximum number of digits repeated correctly in either one of two trials is the response variable. Digit span forwards and digit span 
backwards were separate response variables, and probably measure different aspects of the function domain of memory. ${ }^{25}$ Versions of this test have detected behavioural impairments in workers exposed to lead. ${ }^{4510}$

Santa Ana manual dexterity test

The Santa Ana manual dexterity test measures manual dexterity. ${ }^{26}$ The subject must rotate pegs through $180^{\circ}$. The pegs are arranged in four rows of 12 pegs on a rectangular board. The number of pegs rotated in $30 \mathrm{~s}$ is the response variable. The test was repeated for both the preferred and non-preferred hand. Several studies of lead workers found impairments on versions of this test. ${ }^{510}$

\section{Digit symbol}

Digit symbol measures perceptual speed. ${ }^{24}$ The subject is presented with a key at the top of the page with numbers one to nine displayed with their respective matching symbols. Below are blank blocks with digits above. The subject must copy the appropriate matching symbol for each digit based on the key at the top of the page. The number of correct symbols drawn in the 90 second test period is the response variable. Versions of this test have detected behavioural impairments in foundry workers ${ }^{16}$ and workers manufacturing ethyl lead. ${ }^{13}$

\section{Benton visual retention}

Benton visual retention measures visual memory. ${ }^{27}$ The subject is shown a drawing for 10 seconds composed of geometric figures. After the drawing is removed, the subject is shown four similar looking drawings, only one of which is a true replica of the original. The subject must identify the correct drawing. The number correct in 10 trials is the response variable. Versions of this test were positively associated with poorer performance among smelter ${ }^{6}$ and ethyl lead workers. ${ }^{13}$

\section{Pursuit aiming}

Pursuit aiming measures fine motor control and perceptual speed. ${ }^{26}$ With a pencil, the subject is instructed to dot the centre of circles, as quickly and as accurately as possible. The circles, $2 \mathrm{~mm}$ in diameter, are arrayed on a paper sheet in 30 columns by 40 rows. Excluding outliers, the number of dotted circles in two $30 \mathrm{~s}$ trials is the response variable. This test has not usually been in test batteries applied to workers exposed to lead.

\section{STATISTICAL METHODS}

To test the hypothesis of an association between exposure to lead and performance for each neurobehavioural test variable, multivariate models were constructed that incorporated age and education as mandatory covariates and one of the four exposure variables as an index of exposure. Models with additional, albeit weaker, or uncertain covariates (alcohol consumption, medical conditions possibly affecting performance, and previous job involving solvent exposure) were also constructed to determine whether expo- sure coefficients changed in magnitude or direction. Because the results differed little with either modelling strategy, models with the expanded variable list only are presented. Alternative statistical models with multivariate analysis of covariance (MANCOVA), in which continuous variables of exposure to lead had been categorised, gave nearly identical results.

In analyses of dichotomous exposure variables, analysis of covariance was used that gave results essentially the same as simple $t$ tests. In analyses with blood lead concentration, multiple linear regressions models were used. These included an additional indicator variable for location (smelter).

All $2 \times 2$ interactions between exposure and covariates were examined in models. The few significant but isolated interactions found between exposure and age on the neurobehavioural function tests were plotted.

For the analysis of the symptoms that occurred in the year before testing, prevalence ratios were derived from $2 \times 2$ tables to provide a measure of the association between exposure to lead in dichotomous groups and presence or absence of symptoms. The $95 \%$ Confidence intervals (95\% CIs) were based on normal approximations.

All levels of significance testing were set with a one sided $a$ of 0.05 , given the weight of the scientific literature about adverse (rather than beneficial) effects. Two subjects with extreme results that probably Table 1 Characteristics of exposed and non-exposed
workers

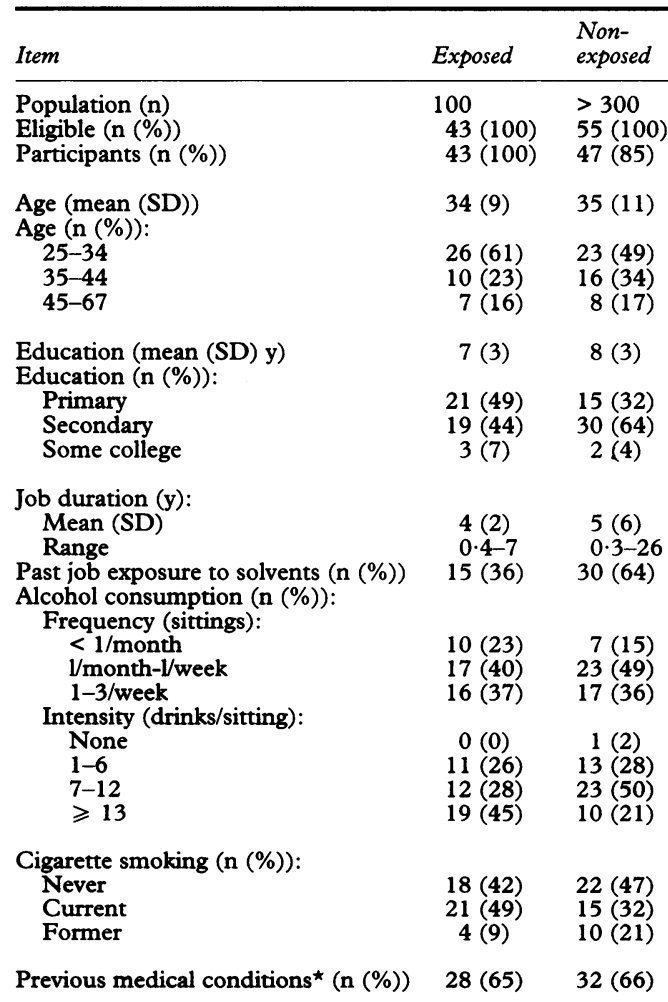

^Includes hand fractures (23 reports), whiplash (19), current medicine takers (16), loss of consciousness (16), migraine headaches (10), wrist conditions (8), arthritis (5), anaemia (3), emotional illness (3), Bell's palsy (1), and seizures (1). Missing data were excluded in calculations of percentages. 
Table 2 Distribution of blood lead concentration

\begin{tabular}{|c|c|c|c|}
\hline Item & Current & Peak & $T W A$ \\
\hline \multicolumn{4}{|c|}{ Concentration $(\mu \mathrm{mol} / \mathrm{l})$ : } \\
\hline Range & $0.43-3.24$ & $0 \cdot 43-5 \cdot 47$ & $0.43-3.63$ \\
\hline Mean (SD): & $1.40(0.77)$ & $1.79(1.30)$ & $1.50(1.26)$ \\
\hline Exposed & $2.03(0.58)$ & $2.85(0.97)$ & $2.27(0.58)$ \\
\hline Non-exposed & $0.73(0.29)$ & $0.73(0.29)$ & $0.73(0.29)$ \\
\hline \multicolumn{4}{|c|}{ Distribution of concentration (n (\%)): } \\
\hline$<0.48$ & $3(4)$ & $3(4)$ & $3(4)$ \\
\hline $0 \cdot 48-1 \cdot 19$ & $37(44)$ & $34(41)$ & $33(39)$ \\
\hline $1 \cdot 20-1 \cdot 89$ & $17(20)$ & $11(13)$ & $19(23)$ \\
\hline $1.90-2.89$ & $22(26)$ & $15(18)$ & $23(27)$ \\
\hline $2 \cdot 90-3 \cdot 86$ & $5(6)$ & $15(18)$ & $6(7)$ \\
\hline$\geqslant 3.87$ & $0(0)$ & $6(7)$ & $0(0)$ \\
\hline
\end{tabular}

Missing data were excluded in calculations of percentages.

arose from current medical conditions (arthritis), were excluded. Blood lead concentrations were unavailable for seven workers at the glass factory. Although multiple comparisons were unavoidable, the results were interpreted in the context of overall patterns with biological coherence, rather than single isolated significant associations.

\section{Results}

RESPONSE AND CHARACTERISTICS OF SUBJECTS All $43(100 \%)$ of the eligible long term smelter workers and $47(85 \%)$ of 55 glass factory workers participated (table 1). The exposed group was on average slightly younger, slightly less educated, had proportionately fewer men with a history of occupa-

Table 3 Correlation coefficients (Pearson $r$ ) between blood lead concentration and covariates

\begin{tabular}{lccc}
\hline \multirow{4}{*}{ Item } & \multicolumn{2}{l}{ Blood lead concentration } & \\
\cline { 2 - 4 } & Current & Peak & $T W A$ \\
\hline Peak lead concentration & $0.84^{\star \star}$ & - & - \\
TWA concentration & $0.95^{\star \star}$ & $0.94^{\star \star}$ & - \\
Age & & 0.11 & 0.02 \\
Education & -0.04 & -0.11 & -0.03 \\
Alcohol (drinks/sitting) & 0.003 & 0.09 & 0.10 \\
Alcohol (sittings/week) & -0.16 & -0.06 & -0.09 \\
\hline
\end{tabular}

$\star \star \mathrm{P}<0.01$.

Table 4 Neurobehavioural function in workers exposed and non-exposed to lead

\begin{tabular}{|c|c|c|c|c|}
\hline & Exposed & Non-exposed & & \\
\hline Test & mean $(S D)^{*}$ & mean $(S D)$ & $P$ value & Effect (\%) \\
\hline $\begin{array}{l}\text { Profile of mood states: } \\
\text { Tension-anxiety } \\
\text { Hostility } \\
\text { Fatigue } \\
\text { Depression } \\
\text { Vigour } \\
\text { Confusion }\end{array}$ & $\begin{array}{r}11 \cdot 5(6) \\
8 \cdot 0(8) \\
5 \cdot 4(5) \\
7 \cdot 3(8) \\
19 \cdot 1(4) \\
6 \cdot 1(5)\end{array}$ & $\begin{array}{r}10 \cdot 6(6) \\
6 \cdot 7(7) \\
4.9(4) \\
6 \cdot 0(6) \\
19 \cdot 0(4) \\
5 \cdot 6(4)\end{array}$ & $\begin{array}{l}0.24 \\
0.20 \\
0.34 \\
0.20 \\
0.42 \\
0.27\end{array}$ & $\begin{aligned} 8 & \downarrow \\
19 & \downarrow \\
10 & \downarrow \\
22 & \downarrow \\
1 & \downarrow \\
9 & \downarrow\end{aligned}$ \\
\hline $\begin{array}{l}\text { Simple reaction time (ms) } \\
\text { Digit symbol (n correct) } \\
\text { Digit span (digits recalled): }\end{array}$ & $\begin{array}{l}291(59) \\
38 \cdot 0(12)\end{array}$ & $\begin{array}{l}313(66) \\
37 \cdot 1(14)\end{array}$ & $\begin{array}{l}0.06 \\
0.33\end{array}$ & $\begin{array}{l}7 \uparrow \\
2 \uparrow\end{array}$ \\
\hline $\begin{array}{l}\text { Forward } \\
\text { Backward }\end{array}$ & $\begin{array}{l}5 \cdot 2(2) \\
4 \cdot 0(2)\end{array}$ & $\begin{array}{l}5 \cdot 2(2) \\
4 \cdot 3(2)\end{array}$ & $\begin{array}{l}0.19 \\
0.47\end{array}$ & $\begin{array}{l}0= \\
7 \downarrow\end{array}$ \\
\hline $\begin{array}{l}\text { Santa Ana peg board (n completed): } \\
\text { Preferred hand } \\
\text { Non-preferred hand } \\
\text { Benton (n correct) } \\
\text { Pursuit aiming ( } \mathrm{n} \text { completed) }\end{array}$ & $\begin{array}{c}41 \cdot 6(6) \\
36 \cdot 9(6) \\
7 \cdot 2(2) \\
136(42)\end{array}$ & $\begin{array}{r}42 \cdot 6(7) \\
37 \cdot 4(7) \\
6 \cdot 8(2) \\
144(50)\end{array}$ & $\begin{array}{l}0.20 \\
0.18 \\
0.19 \\
0.36\end{array}$ & $\begin{array}{l}2 \downarrow \\
1 \\
6 \uparrow \\
6 \downarrow\end{array}$ \\
\hline
\end{tabular}

*Analysis of covariance, means adjusted for age, education, alcohol intake, previous occupa^Analysis of covariance, means adjusted for age, education, alcohol intake, previous occupa-
tional exposure to solvents, medical conditions.

†Effect in percentage difference (exposed-non-exposed)/non-exposed $\downarrow$ indicates poorer performance in exposed group.

$\ddagger$ Profile of mood states scale: 1 (best) to 20 (worst). tional solvent exposure, but proportionately more men who were heavy drinkers and current cigarette smokers. The pattern of taking medicine, and medical conditions, temporary mental or physical conditions, and sleep the night before testing was similar in both the exposed and non-exposed groups.

EXPOSURE AND POTENTIAL CONFOUNDING

The mean (range) current blood lead concentrations were $1.40(0.43$ to 3.24$) \mu \mathrm{mol} / 1$ (9-67 $\mu \mathrm{g} / \mathrm{dl}$ ) (table 2). Similarly, peak concentration ranged from 0.43 to $5.47 \mu \mathrm{mol} / 1$ (9-113 $\mu \mathrm{g} / \mathrm{dl})$ and nearly a quarter of the men registered a peak concentration above $2.90 \mu \mathrm{mol} / 1$ $(60 \mu \mathrm{g} / \mathrm{dl})$. The TWAs were intermediate between current and peak.

Correlations between the quantitative variables of exposure to lead (including both smelter and glass factory workers) and the covariates of age, education, and alcohol consumption (table 3) indicate that younger workers tended to have higher current blood lead concentrations, but that older workers tended towards higher peak concentrations and higher TWAs. Workers with higher levels of education tended to have lower peak or TWA lead concentrations. Alcohol consumption was inconsistently associated with exposure. More highly exposed workers (whether classified by current, peak, or TWA concentration) tended to drink less often (fewer sittings), but with greater intensity (more drinks a sitting) than workers with less exposure.

Whether current dichotomous or quantitative exposure classifications to lead were used, the distribution of covariates indicated potentially competitive confounding tendencies, which, although weak, generally would mask (negative confounding) neurobehavioural effects related to exposure.

\section{NEUROBEHAVIOURAL TESTS}

Overall, in 10 of 14 subtests (table 4), the exposed group had poorer performance than the non-exposed, but none of the observed differences reached significance. Likewise, of 14 subtests, poorer performance was associated with increasing blood lead concentration in 11 for current blood lead concentration, 10 for peak, and 12 for TWA, (table 5).

Poorer scores on the profile of mood states were consistently associated with exposure to lead, whether defined as dichotomous categories (table 4) or blood lead concentrations (table 5). The difference between exposed and non-exposed workers ranged from $2 \%$ to $22 \%$ (table 4) with hostility and depression scores most pronounced. Dose-related (fig) and significantly poorer (table 5) mood states were found for tension-anxiety (current), hostility (current, TWA), and depression (current, peak, and TWA).

Simple reaction time was slower among lead workers for current lead and TWA concentration, but the reverse was true for dichotomous and peak exposure variables (tables 4 and 5). Performance on the digitsymbol test was consistently associated with higher exposure to lead but not significantly 
Table 5 Multiple linear regression of neurobehavioural function in workers and lead exposure indices

\begin{tabular}{|c|c|c|c|}
\hline \multirow[b]{2}{*}{ Test } & Current & Peak & $T W A$ \\
\hline & Coefficient $(P \text { value })^{*}$ & Coefficient ( $P$ value) & Coefficient (P value) \\
\hline \multicolumn{4}{|l|}{ Profile of mood states: } \\
\hline Tension-anxiety & $0.17(0.009) \downarrow$ & $0.05(0.12) \downarrow$ & $0.10(0.06) \downarrow$ \\
\hline Hostility & $0.20(0.01) \downarrow$ & $0.09(0.06)$ & $0.15(0.04)$ \\
\hline Fatigue & $0.09(0.07) \downarrow$ & $0.03(0.19) \downarrow$ & $0.05(0.19)$ \\
\hline Depression & $0.22(0.003) \downarrow$ & $0.14(0.003) \downarrow$ & $0.21(0.004) \downarrow$ \\
\hline Vigour & $0.03(0.25) \downarrow$ & $-0.003(0.44) \uparrow$ & $0.005(0.45) \downarrow$ \\
\hline Confusion & $0.07(0.10) \downarrow$ & $0.03(0.20) \downarrow$ & $0.05(0.18) \downarrow$ \\
\hline Simple reaction time (ms) & $0.34(0.32) \downarrow$ & $-0.08(0.44) \uparrow$ & $0.53(0.23) \downarrow$ \\
\hline Digit symbol (n correct) & $0.05(0.35) \downarrow$ & $0.03(0.36) \downarrow$ & $0.03(0.40) \downarrow$ \\
\hline \multicolumn{4}{|l|}{ Digit span (digits recalled): } \\
\hline Forward & $0.0004(0.49) \uparrow$ & $-0.004(0.38) \downarrow$ & $-0.005(0.40) \downarrow$ \\
\hline Backward & $-0.02(0.10) \downarrow$ & $0.004(0.35) \uparrow$ & $-0.006(0.36)$ \\
\hline \multicolumn{4}{|l|}{ Santa Ana peg board (n completed): } \\
\hline Preferred & $-0.05(0.25) \downarrow$ & $-0.02(0.30) \downarrow$ & $-0.007(0.46) \downarrow$ \\
\hline Non-preferred & $-0.04(0.29) \downarrow$ & $0.03(0.23) \uparrow$ & $0.07(0.18) \uparrow$ \\
\hline Benton ( $\mathrm{n}$ correct) & $0.001(0.48) \uparrow$ & $-0.002(0.42) \downarrow$ & $-0.007(0.46) \downarrow$ \\
\hline Pursuit aiming ( $\mathrm{n}$ completed) & $0.12(0.41) \uparrow$ & $-0.006(0.49) \downarrow$ & $0.07(0.18) \uparrow$ \\
\hline
\end{tabular}

^Multiple linear regression including the covariates of age, education, alcohol intake, previous occupational exposure to solvents, medical conditions, and location (glass factory $v$ smelter) $P$ values are one sided.

Subtests of profile of mood states as a function of current blood lead category: $0 \cdot 4-0.9 \mu \mathrm{molll}(n=35)$, $1 \cdot 0-1 \cdot 9 \mu \mathrm{moll} /(n=23)$, $2 \cdot 0-3 \cdot 24 \mu \mathrm{molll}(n=25)$.

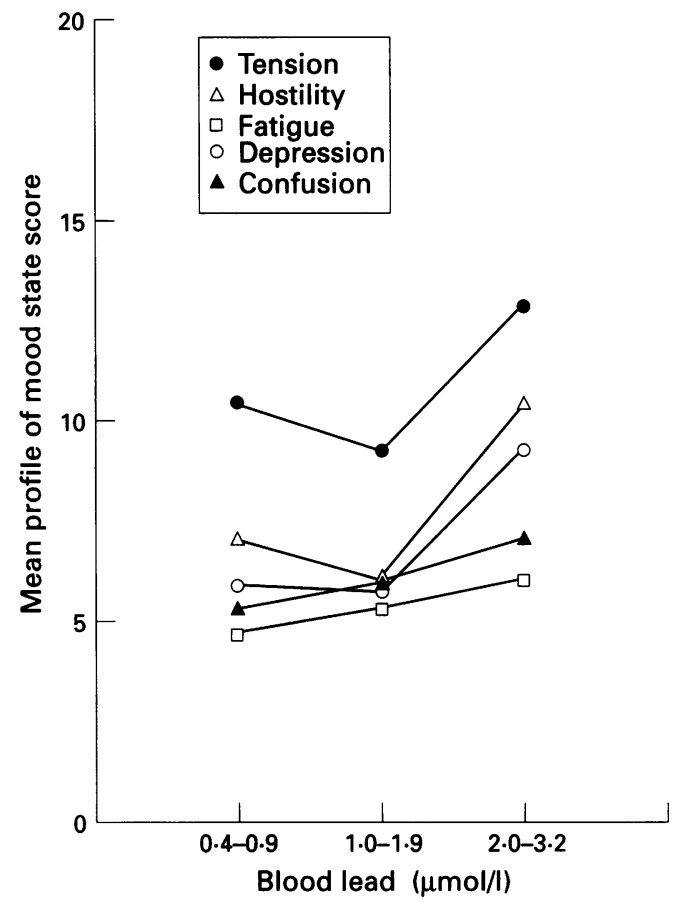

Table 6 Annual period prevalence of symptoms among lead smelter workers by exposure category

\begin{tabular}{|c|c|c|c|}
\hline \multirow[b]{2}{*}{ Symptom } & \multirow{2}{*}{$\frac{\text { Exposed }}{n(\%)}$} & \multirow{2}{*}{$\frac{\text { Non-exposed }}{n(\%)}$} & \multirow[b]{2}{*}{$R R(95 \% C I)$} \\
\hline & & & \\
\hline \multicolumn{4}{|l|}{ Central nervous system: } \\
\hline Said to be forgetful by friends or family & $20(47)$ & $14(30)$ & $1.5(0.9-2.7)$ \\
\hline Often forget to do important activities & $16(37)$ & $12(26)$ & $1.5(0 \cdot 8-2 \cdot 7)$ \\
\hline Difficulties concentrating & $21(49)$ & $13(28)$ & $1.8(1.0-3 \cdot 1)$ \\
\hline Often angry or upset without reason & $20(47)$ & $10(21)$ & $2 \cdot 2(1 \cdot 2-4 \cdot 1)$ \\
\hline Often downcast or sad without reason & $20(47)$ & $10(21)$ & $1.6(0.8-3.3)$ \\
\hline Difficulties in making decisions & $11(27)$ & $10(21)$ & $1 \cdot 2(0 \cdot 6-2 \cdot 6)$ \\
\hline Feeling abnormally tired & $12(28)$ & $6(13)$ & $2 \cdot 2(0 \cdot 9-5 \cdot 3)$ \\
\hline Sensation of falling on arising or walking & $10(23)$ & $7(15)$ & $1.6(0.7-3.7)$ \\
\hline \multicolumn{4}{|l|}{ Peripheral nervous system: } \\
\hline Pins and needles in arms & $17(40)$ & $12(26)$ & $1 \cdot 6(0 \cdot 8-2 \cdot 8)$ \\
\hline Pins and needles in legs & $14(33)$ & $14(30)$ & $1 \cdot 1(0 \cdot 6-2 \cdot 0)$ \\
\hline Loss of strength in arms & $11(26)$ & $8(17)$ & $1.5(0.7-3.4)$ \\
\hline Loss of strength in legs & $10(23)$ & $10(21)$ & $1 \cdot 1(0 \cdot 5-2 \cdot 4)$ \\
\hline Difficulties in clasping buttons & $3(7)$ & $1(2)$ & $3 \cdot 3(0 \cdot 4-30)$ \\
\hline \multicolumn{4}{|l|}{ Gastrointestinal: } \\
\hline Metallic taste in mouth & $10(23)$ & $12(26)$ & $0.9(0.4-1.9)$ \\
\hline Joint pain & $20(47)$ & $12(26)$ & $1.8(1.0-3 \cdot 3)$ \\
\hline Colic or cramp & $14(33)$ & $11(33)$ & $1.4(0 \cdot 7-2 \cdot 7)$ \\
\hline Diarrhoea & $3(7)$ & $2(4)$ & $1.6(0.3-9.4)$ \\
\hline Constipation & $9(21)$ & $5(11)$ & $2.0(0.7-5.4)$ \\
\hline Loss of appetite & $9(21)$ & $6(13)$ & $1.6(0.6-4 \cdot 2)$ \\
\hline \multicolumn{4}{|l|}{ Other: } \\
\hline Pressure in chest & $14(33)$ & $11(23)$ & $1 \cdot 4(0 \cdot 7-2 \cdot 7)$ \\
\hline Difficulty in falling asleep & $18(42)$ & $12(26)$ & $1.6(0.9-3.0)$ \\
\hline
\end{tabular}

Missing data were excluded in calculations of percentages. so. Smaller digit span (forward or backward) was not consistently or significantly associated with increasing indices of exposure to lead. Fewer pegs turned with the preferred hand in the Santa Ana pegboard was associated with exposure to lead, but this was not found for the non-preferred hand (table 5). No consistent or significant association between performance and lead exposure index was found in either the Benton or pursuit aiming subtests (tables 4 and 5).

PREVALENCE OF SUBJECTIVE SYMPTOMS

The frequency of symptoms suggestive of central and peripheral nervous system problems was consistently higher among the exposed group (table 6). Significantly increased relative risks were found for difficulties in concentration $(R R=1 \cdot 8)$, often being angry or upset without reason $(R R=2 \cdot 2)$, and feeling abnormally tired $(R R=2 \cdot 2)$. Although the prevalence of gastrointestinal and other symptoms was higher among exposed workers, only joint pain $(R R=1 \cdot 8)$ reached significance.

\section{Discussion}

The central findings of this study are altered mood states related to blood lead concentrations that reflected current, peak, and TWAs. Other aspects of performance such as memory (digit span, Benton), perceptual speed (digitsymbol), reaction time, and manual dexterity (Santa Ana pegboard) generally tended to be poorer with increasing exposure, but the magnitude of the effect was small.

This study has several strengths and limitations. Because participation was very high, non-response bias was not a concern. Because significant layoffs of long term smelter workers occurred shortly before the study began, concerns may be raised whether the surviving population was truly representative. Although data are not available to assess this, it seems unlikely that a less productive and less healthy group would have been retained.

A non-exposed control group within the lead smelter was not available because of widely shared exposures from job rotation. Moreover, new workers were disproportionately 
younger and management did not support inclusion of new workers in the study. A nearby glass plant drawing from the same general worker population was selected as a source of the non-exposed group. Further, a plant indicator variable was included in all statistical analyses with blood lead concentration to pick up potential association related to population selection or test administration at the two different sites. Quantitative effects of exposure persisted despite the inclusion of this site variable in the analyses of mood states.

An important strength of this study was the availability of current and historical measurements of blood lead concentration so that dose-response relations could be evaluated. The range $(0.43-3.24 \mu \mathrm{mol} / \mathrm{l})$ and duration (mean of four years) of current exposure to lead were low compared with similar studies. The small effects found were consistent with what would be expected at the low end of the dose-response curve.

This study was limited to detect small differences because of the relatively small sample size. Power calculations of subtests of the NCTB based on previous studies in Venezuelan industrial workers indicate that in comparisons of 50 exposed and 50 nonexposed workers, only simple reaction time would be able to detect a $10 \%$ difference in means with $80 \%$ power with $95 \%$ CI ( $a=$ 0.05 , one sided).

The smelter workers and glass factory workers seemed to be comparable in basic demography, and were selected to reflect comparable intellectual and work demands. Potentially confounding variables of age, education, alcohol consumption, past occupational exposure to solvents, medical conditions, and site were included in multivariate models. Models adjusted for age and education, and models with $2 \times 2$ interaction terms only yielded small differences compared with main effects models with the expanded set of covariates. The covariates consistently predicted neurobehavioural performance as expected: poorer performance associated with increasing age, decreasing education, increasing alcohol consumption, and previous jobs exposed to solvents. This also supports the validity of the models themselves. Symptoms of depression and of spontaneous anger and upset that were significantly increased (table 6) reinforce the findings of the altered mood scales (hostility and depression). This internal consistency lends support to the strength of the findings.

Internal consistency was also found between the measures of lead exposure. Coefficients and $\mathbf{P}$ values of multiple linear regression models were usually of the same sign and magnitude no matter which exposure indices were used: current, peak, or TWA, although the current concentration was more strongly and more often significantly associated with altered mood states. Cumulative exposure (the sum of the products of concentration and time- the numerator of the equation for TWA) has been used in several studies as an additional exposure index. ${ }^{1316}$ With cumulative exposure to lead $(\mu \mathrm{mol} / 1 \times$ years), visual (Benton: $\beta=-0.003, P=0.01$ ), auditory memory (digit span: $\beta=-0.002, \mathbf{P}=$ 0.06 ) and manual dexterity (Santa Ana pegboard: $\beta=-0.01, \mathbf{P}=0.01$ ) also showed significant dose-response relations of poorer performance. Age and cumulative exposure were strongly and positively associated (Pearson $r=0.42$ ), raising the possibility of confounding by age. This seemed to be confirmed by analyses of covariance (not presented) in which significant associations for Benton, digit span, or Santa Ana were diminished among cumulative exposure categories (high, medium, or low), after adjustment for age as well as the other covariates.

Another source of potential bias was that neither the subjects nor the interviewer were blinded to exposure status. Although this may be thought to have skewed results in exposed $v$ non-exposed comparisons, it is less likely to be an explanation of dose-response.

The results of this study bear close resemblance to those of Baker et $a l_{,}{ }^{2}$ except that the overall exposure effect occurred at a slightly lower average exposure $(1.40 v 1.60 \mu \mathrm{mol} / \mathrm{l})$. Most previous studies did not include profile of mood states or similar checklists, but, of those that did, ${ }^{12} 7$ the results are consistent: moods indicative of depression, anger, hostility, fatigue, or confusion were more pronounced among exposed workers.

Several workers have suggested that a threshold for adult neurobehavioural effects found by psychometric testing is associated with blood lead concentrations of between $1.93-2.41 \mu \mathrm{mol} / 1 \quad(40-50 \mu \mathrm{g} / \mathrm{dl})$. Studies for which this is most obvious relied on Wechsler adult intelligence subtests (block design, digit span, digit-symbol), simple or choice reaction time tests, or newer tests based on information processing theory. ${ }^{15} 17$ These studies also often reported considerably slower peripheral nerve conduction among exposed workers. Our findings and those of others ${ }^{127}$ suggest that altered mood measured by profiles of mood states and similar tests may be among the earliest psychometrically detectable changes due to low exposure to lead.

To our knowledge, this is the first study in South America that used the WHO neurobehavioural core test battery to confirm adverse effects of a low occupational exposure to lead. The findings support efforts to reduce lead exposures to the lowest possible level and to follow-up workers exposed to lead over a longer period to evaluate the degree to which improved performance results from reduced exposures.

We acknowledge the workers, management, and unions at the Fundición del Centro and Produvisa, Aragua, Venezuela for supporting and participating in the study. The University of supporting and participating in the study. The University of Carabobo and the Venezuelan Ministry of Health and Social Assistance are gratefully acknowledged for the institutional upport of NAM during his stay in Venezuela. Appreciation is expressed to the United States National Institute for Occupational Safety and Health for technical assistance. Drs Evelin Escalona, Nicolas Santaella, Magola Fernández, and other members of the Occupational Health Unit, University of Carabobo are acknowledged for translating and pilot testing the test battery and processing blood samples. 
1 Baker EL, White RF, Pothier L, Berkey CS, Dinse GE, Travers $\mathrm{PH}$, et al. Occupational lead neurotoxicity: improvement in behavioural effects after reduction in exposure. $\mathrm{Br}$ F Ind $\mathrm{Med}$ 1985;42:507-16.

2 Baker EL, Feldman RG, White RF, Harley JP, Niles CA, Dinse GE, Berkey CS. Occupational lead neurotoxicity: a behavioural and electrophysiological evaluation. $\mathrm{Br} \mathcal{F}$ Ind Med 1984;41:352-61.

3 Campara P, D'Andrea F, Micciolo R, Savonitto C, Tansella M, Zimmermann-Tansella C. Psychological performance of workers with blood-lead concentration below the current threshold limit value. Int Arch Occup Environ Health 1984;53:233-46.

4 Grandjean P, Arnvig E, Beckmann J. Psychological dysfunctions in lead-exposed workers: relation to biologica parameters of exposure. Scand $\mathcal{f}$ Work Environ Health 1978;4:295-303.

5 Hanninen H, Hernberg S, Mantere P, Vesanto R, Jalkanen M. Psychological performance of subjects with low exposure to lead. F Occup Med 1978;20:683-9.

6 Hogstedt C, Hane M, Agrell A, Bodin L. Neuropsychological test results and symptoms among workers with well-defined long-term exposure to lead. Br F Ind Med 1983;40:99-105.

7 Johnson B, Burg JR, Xinteras C, Handke JL. A neuroohnson B, Burg JR, Xinteras C, Handke JL. A neurobehavioral examination of workers from a prim
ferrous smelter. Neurotoxicology 1980;1:561-81.

8 Kirby H, Nielsen CJ, Nielsen VK, Gyntelberg F. Subjective symptoms after long term lead exposure in secondary lead smelting workers. Br f Ind Med 1983; 40:314-7.

9 Zimmerman-Tansella C, Campara P, D'Andrea F Saronitto C, Tansella M. Psychological and physical complaints of subjects with low exposure to lead Hum Toxicol 1983;2:615-23.

10 Mantere P, Hanninen $\mathrm{H}$, Hernberg S, Lukkonen R. A prospective follow-up study on psychological effects in prospective follow-up study on psychological effects in workers exposed to low levels

11 Repko JD, Morgan BB, Nicholson J. Behavioral effects of occupational exposure to lead. Cincinnati: Nationa Institute for Occupational Safety and Health, 1975 (USDHEW (NIOSH) Publ No 75-184.)

12 Repko JD, Corum CR, Jones PD, Garcia LS. The effects of inorganic lead on behavioral and neurologic function. Cincinnati: National Institute for Occupational Safety and Health, 1978.
13 Schwartz BS, Bolla KI, Stewart W, Ford DP, Agnew J, Frumkin H. Decrements in neurobehavioral performance associated with mixed exposure to organic and inorganic lead. Am F Epidemiol 1993;137:1006-21.

14 Stollery BT, Broadbent DE, Banks HA, Lee WR. Shor term prospective study of cognitive functioning in lead workers. Br ₹ Ind Med 1991;48:739-49.

15 Stollery BT, Banks HA, Broadbent DE, Lee WR. Cognitive functioning in lead workers. $\mathrm{Br} F$ Ind $\mathrm{Med}$ 1989;46:698-707

16 Valciukas JA, Lilis R, Eisinger J, Blumberg WE, Fischbein A, Selikoff IJ. Behavioral indicators of lead neurotoxicA, Selikoff IJ. Behavioral indicators of lead neurotoxicity: results of a clinical field

17 Williamson AM, Teo RKC. Neurobehavioural effects of occupational exposure to lead. $\mathrm{Br} F$ Ind Med 1986;43 374-80.

18 American Conference of Governmental and Industrial Hygienists. Threshold limit values and biological exposur indices for 1990-1991. Cincinnati: ACGIH, 1991.

19 World Health Organisation. Operational guide for the WHO neurobehavioral core test battery; and WHO. Field evaluaWHO, 1986.

20 Anger WK, Cassito MG, Liang You-Xin, et al. Comparison of performance from three continents on Comparison of performance from three continents on the WHO-recommended neurobehavior

21 Escalona E, Yanes L, Feo O, Maizlish N. Neurobehaviora evaluation of Venezuelan workers exposed to organi solvent mixtures. Am F Ind Med 1995;27:15-27.

22 Letz $\mathrm{R}$. The neurobehavioral evaluation system: an international effort. In: Johnson BL, Anger WK, Durao A, Xinteras $C$, eds. Advances in neurobehavioral toxicolog Chelsea, MI: Lewis, 1990:189-201.

23 McNair DM, Lorr M, Dropleman LF. EITS ManualProfile of mood states. San Diego: Educational Testing Service, 1971.

24 Wechsler D. The measurement and appraisal of adult intelligence. Baltimore: Williams and Wilkins. 1958

25 Lezak MD. Neuropsychological assessment, 2nd ed. New York: Oxford University Press, 1983

26 Fleishman EA. Dimensional analysis of psychomoto abilities. Fournal of Experimental Psychology 1954;48: 437-54.

27 Benton A. The revised visual retention test. Ames, Iowa: State University of Iowa, 1963.

\section{Rejected manuscripts}

From February 1994, authors whose submitted articles are rejected will be advised of the decision and one copy of the article, together with any reviewers' comments, will be returned to them. The fournal will destroy remaining copies of the article but correspondence and reviewers' comments will be kept. 